\title{
Self-Esteem and Coping among Children with Borderline Intelligence and Average Intelligence
}

\author{
Dr. Hosamani Marilingappa ${ }^{1} *$
}

\section{ABSTRACT}

The aim of the study was to understand self esteem and coping among children with borderline intelligence and average intelligence. The sample consists of two groups, 30 children of borderline intelligence and 30 children of average intelligence in the age ranged of 8 to12 years and studying in 4th to 6th. Individuals with any major physical disability and psychological problem were not considered for the study. Self-esteem and coping scale were administered to the children with borderline intelligence and average intelligence. The scales were scored appropriately. Mean, SD and ' $\mathrm{t}$ ' value were determined to compared difference between borderline intelligence and average intelligence children on self esteem and coping by using the t-test.

Result confirmed that there were the children with average intelligence showed significantly less self esteem than children with borderline intelligence. As there was significant difference in self esteem between children with borderline intelligence and average intelligence, the results are not according to the hypothesis stated that there will be no significant difference in self-esteem between borderline intelligence and average intelligence children.

The children with borderline intelligence show significantly less active coping than children with average intelligence. The children with borderline intelligence show significantly less avoid coping than children with average intelligence. The children with borderline intelligence show significantly less support coping than children with average intelligence. As there was significant difference in active coping, avoid coping and support coping between children with borderline intelligence average intelligence, the results are not according to the hypothesis stated that there will be no significant difference in support coping between borderline intelligence and average intelligence children.

Keywords: Self-Esteem, Coping, Children, Intelligence.

\footnotetext{
${ }^{1}$ Assistant Professor of Psychology and P.G Co-Ordinator, Maharani Womens Arts,Commerce And Management College Sheshadri Road Bangalore

*Responding Author

(C) 2016 I H Marilingappa; licensee IJIP. This is an Open Access Research distributed under the terms of the Creative Commons Attribution License (http://creativecommons.org/licenses/by/2.0), which permits unrestricted use, distribution, and reproduction in any Medium, provided the original work is properly cited.
} 
Intelligence is the ability to solve problems and to adapt to and learn from life's everyday experiences. The ability to solve problems The capacity to adapt and learn from experiences Includes characteristics such as creativity and interpersonal skills The mental abilities that enable one to adapt to, shape, or select one's environment The ability to judge, comprehend, and reason The ability to understand and deal with people, objects, and symbols The ability to act purposefully, think rationally, and deal effectively with the environment Intelligence Quotient (IQ) : Measure of intelligence that takes into account a child's mental and chronological age. Mental age (MA): the typical intelligence level found for people found for people at a given chronological age. Chronological age (CA): the actual age of the child taking the intelligence test people whose mental age is equal to their chronological age will always have an IQ of 100. If the chronological age exceeds mental age - below-average intelligence (below 100). If the mental age exceed the chronological age-above-average intelligence (above 100).

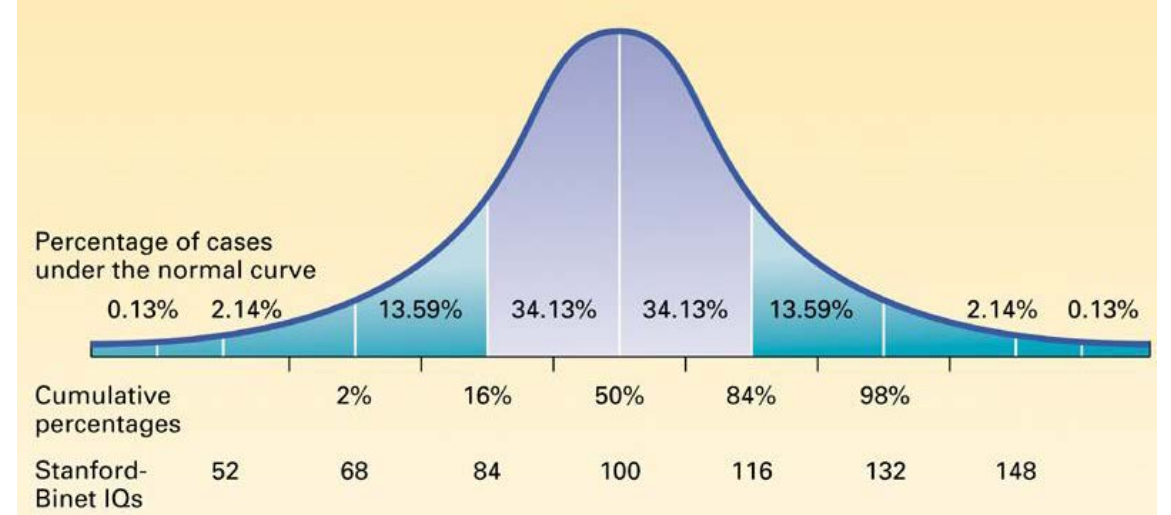

The normal distribution: most of the population falls in the middle range of scores between 84 and 116.

Very superior Intelligence (gifted)-Above 13

Superior Intelligence - 120 to 129

High Average Intelligence - 110 to 119

Average Intelligence - 90 to 109

Intelligence -80 to 89
Borderline Intellectual Functioning -71 to 79

Mild Mental Retardation - 55 to 70

Moderate Retardation - 40 to 54

Severe Mental Retardation -25 to 39Low Average

Profound Mental Retardation - Below 25

Intelligence tests were developed for the practical function of selection of selecting students for admission or placement in schools. Originally these tests were not based on any theory of intelligence. They defined intelligence as the ability to do well in school.

\section{BORDERLINE INTELLECTUALS}

Borderline intellectual functioning is a cognitive impairment that applies to people who have lower than average intelligence but do not have intellectual developmental disorder or mental retardation. Borderline intellectual functioning is diagnosed by IQ test scores that are between 71 and 84.Borderline intellectual functioning refers to estimated intelligence quotient scores within the 70 to 75 range on intelligence test with an average of 100 and standard deviation of 15 . The 


\section{Self-Esteem and Coping among Children with Borderline Intelligence and Average Intelligence}

range is called borderline because it is on the borderline of the criteria for diagnosis of intellectual disabilities (historically referred to as mental retardation) in the Diagnostic and Statistical Manual of Mental Disorders.(DSM)

Examples: Consistent scores within the 70 to 75 range are considered suggestive of borderline intellectual functioning and may indicate a mental disability. However, it is recommended that multiple test instruments be administered to confirm a diagnosis. No diagnosis should be made on the basis of a single test.

Borderline intellectual functioning, also called borderline mental retardation, is a categorization of intelligence wherein a person has below average cognitive ability (generally an IQ of 70-85), but deficit is not as severe as intellectual disability (below 70). It is sometimes called below average IQ (BAIQ). This is technically a cognitive impairment however; this group is not sufficiently mentally disabled to be eligible for specialized services. Additionally, the DSM-IVTR codes borderline intellectual functioning as V62.89, which is generally not a billable code, unlike the codes for mental retardation.

During school years, individuals with borderline intellectual functioning are often "slow learners". Although a large percentage of this group fails to complete high school and can often achieve only a low socioeconomic status, most adults in this group blend in with the rest of the population.

\section{AVERAGE INTELLIGENCE}

The narrow definition of IQ is a score on an intelligence test ... where 'average' intelligence, that is the median level of performance on an intelligence test, receives a score of 100 , and other scores are assigned so that the scores are distributed normally about 100, with a standard deviation of 15.

Intelligence tests are one of the most popular types of psychological tests in use today. On the majority of modern IQ tests, the average (or mean) score is set at 100 with a standard deviation of 15 so that scores conform to a normal distribution curve. This means that 68 percent of scores fall within one standard deviation of the mean (that is, between 85 and 115), and 95 percent of scores fall within two standard deviations (between 70 and 130). Why is the average score set to 100 ? Psychometritians utilize a process known as standardization in order to make it possible to compare and interpret the meaning of IQ scores. This process is accomplished by administering the test to a representative sample and using these scores to establish standards, usually referred to norms, by which all individual scores can be compared. Since the average score is 100, experts can quickly can quickly assess individual test scores against the average to determine where these scores fall on the normal distribution. 


\section{Self-Esteem and Coping among Children with Borderline Intelligence and Average Intelligence}

Intelligence tests are designed to measure what is known as crystallized and fluid intelligence. Crystallized intelligence involves your knowledge and skills you have acquired throughout your life while fluid intelligence involves your ability to reason, problem-solve, and make sense of abstract information administered by a licensed psychologist. There are different kinds of intelligence test, but many involve a series of subtests that are designed to measure mathematical abilities, language skills, memory, reasoning skills, and information - processing speed. Scores on theses on these subtests are then combined to form an overall IQ score.

One's IQ score might be a good general indicator of your reasoning and problem - solving abilities, but many psychologists suggest that these tests don't tell the whole story. A few things they don't measure are practical abilities and talents. one might have an average IQ score, but you might also be a great musician, a creative artist, an amazing singer, or a mechanical whiz.

Researchers have also found that IQ scores can change over time. One study looked at the IQ's of teenage subjects during early adolescence and then again four years later. The results revealed that scores varied as much as 20 points over that four - year period.

IQ tests also fail to address things like how curious indies are about the world around and how good is at understanding and managing emotions. Some experts, including writer Daniel Goleman, suggest that emotional intelligence (often referred to as EQ) might actually be more important than IQ. And researchers have found that while having a high IQ can certainly give people and edge in many areas of life, it is certainly no guarantee of life success.

So one need not stress out if one is not a genius, since the vast majority of people aren't geniuses either. Just as having a high IQ doesn’t ensure success, having an average or low IQ doesn't ensure failure or mediocrity. Other factors such as hard work, resilience, perseverance, and overall attitude are important pieces of the puzzle.

\section{SELF-ESTEEM}

One might have heard and seen similar words like "self - image”. "Self perception.” And "self concept”. All these terms refer to the way we view and think about ourselves. As human beings, we have the ability to not only be aware of ourselves but also to place a value or a measure of worth to ourselves or aspects of ourselves. So, self - esteem mutually refers to how we view and think about ourselves and the value that we place on ourselves as a person. Having the human capacity to judge and place value to something is where we might run into problems with self esteem.

Self-esteem is similar to self-worth (how much a person values himself or herself). This can change from day to day or from year to year, but overall self-esteem tends to develop from infancy and keep going until we are adults. 


\section{Self-Esteem and Coping among Children with Borderline Intelligence and Average Intelligence}

Self-esteem also can be defined as feeling capable while also feeling loved. A child who is happy with an achievement but does not feel loved may eventually experience low self-esteem. Likewise, a child who feels loved but is hesitant about his or her own abilities can also develop low self-esteem. Healthy self-esteem comes when a good balance is maintained.

Patterns of self-esteem start very early in life. The concept of success following effort and persistence starts early. Once people reach adulthood, it's harder to make changes to how they see and define themselves.

So, it's wise to think about developing and promoting self-esteem during childhood. As kids try, fail, try again, fail again, and then finally succeed, they develop ideas about their own capabilities. At the same time, they're creating a self-concept based on interactions with other people. This is why parental involvement is key to helping kids form accurate, healthy selfperceptions.

Parents and caregivers can promote healthy self-esteem by showing encouragement and enjoyment in many areas. Avoid focusing on one specific area; for example, success on a spelling test, which can lead to kids feeling that they're only as valuable as their test scores.

\section{COPING}

Oping pretty much describes all the different things people do to manage and reduce the stress they feel as a result of issues, problems or difficult situations that occur. Everyone experiences different levels of stress, and also have different ways of coping, which is completely fine. There isn't a 'right' way to cope - different strategies work well for different people, depending on their personal strengths and skills. Despite this, some coping strategies are seen as less beneficial, because they reduce stress temporarily, but don't reduce it in the long run (and often have other bad impacts). Drugs and alcohol are examples of less effective, and sometimes damaging coping strategies. Positive coping skills are any strategies which people find to reduce stress effectively without future backlash. It is these skills you want to develop to help you manage stressful circumstances.

\section{When good coping strategies help}

Everyone has setbacks in life. Problems can crop up when we least expect, and it's pretty normal for some issues to hang around for a while. This can be particularly the case in situations that aren't straightforward to fix. Effective coping is great for all sorts of life dramas - whether they're relatively minor problems, or larger scale disasters. Examples of life events that require some kind of coping skills include

Exam/study pressures natural disasters - e.g. floods, fires, drought relationship conflict or break downs serious illness. How we choose to manage these sorts of situations can have a big impact on the outcome of the situation, as well as the long-term effects on our mental health. 


\section{METHODOLOGY}

Aim:

- To study self esteem and coping among children with borderline intelligence and average intelligence.

\section{Objectives:}

- To study the difference in self-esteem between borderline intelligence and average intelligence children.

- To study the difference in coping between borderline intelligence and average intelligence children.

\section{Hypotheses:}

- There will be no significant difference in self-esteem between borderline intelligence and average intelligence children.

- There will be no significant difference in coping (active coping, avoid coping and support coping) between borderline intelligence and average intelligence children.

\section{Independent Variable:}

- Children with borderline intelligence and average intelligence.

\section{Dependent Variable:}

- Responses on self-esteem and coping scale.

\section{Sample:}

The sample comprised of 30 each of borderline intelligence and average intelligence children, age ranged between 8 to12 years.

\section{Inclusion Criteria:}

Both boys and girls were considered for the study.

Children studying in $4^{\text {th }}$ to $6^{\text {th }}$ standard were considered for the study.

Children identified as borderline intelligence on Colored Progressive Matrices and reported by teacher were considered for the study. Children identifies as average intelligence on Colored Progressive Matrices and reported by the teacher were considered for the study.

\section{Exclusion Criteria:}

Children with any major physical disability and psychological problem were not considered for the study.

\section{Research Design:}

Between groups design with purposive sampling was opted for the study. 


\section{Tools And Description:}

1. Demographic data sheet (Prepare for the study)

2. The Culture Free Self-Esteem Inventory for Children (Battle, 1981).

3. Children’s coping strategies checklist (Pitts, Tein and Sandler, 1995).

\section{Demographic data sheet (Prepare for the study)}

This was constructed for the study to obtain identifying background information about the child such as name, age, school, sex, class, birth order, family type etc.

\section{Culture Free Self-Esteem Inventory for Children (Battle, 1981)}

The inventory has been developed by Battle (1981). It is a 60-item questions/statement classifiable into 4 subscales. Each question or statement is answered in terms of Yes/No. The 4 subscales are: general self-esteem; social and peer related self-esteem; academic and school related self-esteem; parents and home related self-esteem. An analysis of internal consistency based on the normative sample yielded average coefficient alpha reliabilities (across all age categories) generally in the 0.80 's. Furthermore, when sorted by gender, ethnicity, and disability classification, the data generally demonstrated coefficient alpha reliabilities in the 0.80's suggesting that the instrument is consistent across these categories. A sample of (77) individuals (33 Primary-aged, 20 intermediate aged and 24 adolescent) were tested twice with the culture free self-esteem inventory (CFSEI-3) in a two-week period- average correlations between test scores fell in the (.70s) and (.90s) across all age groups and scales. The authors validated the culture free self-esteem inventory (CFSEI)-3 by comparing its scores with other related tools using three age-category samples. The first study compared the culture free self-esteem inventory (CFSEI-3) with the self-esteem index (SEI), the GSEQ score correlated (.61) with the SEI self-esteem quotient. The second study compared culture free self-esteem inventory (CFSEI-

3) scores with scores from the Piers-Harris children's self- concept scale (PHCSCS) total score correlated (.72) with the culture free self-esteem Inventory (CFSEI-3) GSEQ. A third study compared CFSEI-3 scores with scores from the multidimensional self concept scale (MSCS) using the adolescent sample. According to the manual, MSCS total scores correlated (.78) with culture free self-esteem inventory (CFSEI-3).

\section{Children's coping strategies checklist (Pitts, Tein and Sandler, 1995)}

The active coping factor is comprised of the problem focused coping subscales, which are Cognitive Decision Making (CDM), Direct Problem Solving (DPS), and Seeking Understanding (SU) and the Positive Cognitive Restructuring subscales, which are Positivity (POS), Control (CON), and Optimism (OPT). The Avoidant Coping factor is composed of the following subscales; Avoidant Actions (AVA), Repression (REP), and Wishful Thinking (WISH). The Support Seeking Strategies are the Support for Action (SUPA) and the Support for Feelings (SUPF) subscales. The test-retest reliability coefficients for the individual subscales and the four factors are as follows: Individual Subscales $(n=65)$, Cognitive Decision Making (.68), Direct Problem Solving (.66), Positive Cognitive Restructuring (.71), Seeking Understanding (.56), 
Physical Release of Emotion (.71), Distracting Action (.70), Avoidance Action (.49), Cognitive Avoidance (.61), Problem Focused Support (.75), Emotion Focused Support (.73).

\section{Plan:}

The self-esteem scale and coping scale was administered to the children with borderline intelligence and average intelligence aged between 8-12 years and studying in $4^{\text {th }}$ to $6^{\text {th }}$ standard. The mean scores of self esteem and coping were compared between the children with borderline intelligence and average intelligence to analysis the significant difference on self-esteem and coping scale between borderline intelligence and average intelligence children using the t- test.

\section{Procedure:}

Children aged between 8-12 years and studying in $4^{\text {th }}$ to 6 th standard full filling inclusion criteria i.e. Children identified as borderline intelligence and average intelligence on Colored Progressive Matrices, and not falling under exclusion criteria, i.e. Children with special needs and children with major physical disability and psychological problem and willing to be part of the study were administered self-esteem and coping scale. The scales were scored appropriately. Mean, SD and 't' value were determined to compared difference between borderline intelligence and average intelligence children on self esteem and coping by using the t-test.

\section{Analysis of Result:}

The scales were scored and the mean values of dependent variable self-esteem scale and coping scale were compared to analyses the difference between children with borderline intelligence and average intelligence using t-test.

\section{RESULTS AND DISCUSSION}

The aim of the experiment was to study the self esteem and coping among children with borderline intelligence and average intelligence. Children aged between 8-12 years and studying in $4^{\text {th }}$ to 6 th standard full filling inclusion criteria i.e. Children identified as borderline intelligence and average intelligence on Colored Progressive Matrices, and not falling under exclusion criteria, i.e. Children with special needs and children with major physical disability and psychological problem and willing to be part of the study were administered self-esteem and coping scale. The scales were scored appropriately. Mean, SD and ' $t$ ' value were determined to compared difference between borderline intelligence and average intelligence children on self esteem and coping by using the t-test. 
Self-Esteem and Coping among Children with Borderline Intelligence and Average Intelligence

Table: 1 showing the demographical details of the children with borderline intelligence and average intelligence:

\begin{tabular}{|l|l|l|l|l|l|l|l|l|}
\hline \multirow{2}{*}{ Details } & \multicolumn{3}{l|}{ borderline intelligence } & \multicolumn{3}{l|}{ average intelligence } \\
\cline { 2 - 8 } & Govt. & Private & Govt. & Private & \\
\hline & Girls & Boys & Girls & Boys & Girls & Boys & Girls & Boys \\
\hline N & 8 & 7 & 5 & 10 & 5 & 10 & 9 & 8 \\
\hline Age & $8-12$ years & $8-12$ years & & \\
\hline class & \multicolumn{6}{|l|}{$4^{\text {rd }}$ to $6^{\text {th }}$ standard } & $4^{\text {rd }}$ to $6^{\text {th }}$ standard \\
\hline
\end{tabular}

Table: 2 showing the of mean, SD and 't' value on the self esteem and coping among children with borderline intelligence and average intelligence:

\begin{tabular}{|l|l|l|l|l|}
\hline AREAS & GROUP & MEAN & SD & t \\
\hline \multirow{2}{*}{ Self esteem } & Children with borderline intelligence & 40.80 & 13.02 & \multirow{2}{*}{$0.16^{*}$} \\
\cline { 2 - 5 } & Children with average intelligence & 40.26 & 12.47 & \\
\hline \multirow{2}{*}{ Active coping } & Children with borderline intelligence & 39.76 & 13.16 & \multirow{2}{*}{1.34} \\
\cline { 2 - 4 } & Children with average intelligence & 44.00 & 11.23 & \\
\hline \multirow{2}{*}{ Avoid coping } & Children with borderline intelligence & 33.83 & 8.25 & \multirow{2}{*}{$.87^{*}$} \\
\cline { 2 - 4 } & Children with average intelligence & 35.60 & 7.43 & \multirow{2}{*}{$0.36^{*}$} \\
\hline \multirow{2}{*}{ Support coping } & Children with borderline intelligence & 26.66 & 6.00 & \\
\cline { 2 - 5 } & Children with average intelligence & 27.23 & 5.93 & \\
\hline \multicolumn{2}{|l|}{ P>/0.05* (significant at 0.05 level), } \\
\hline
\end{tabular}

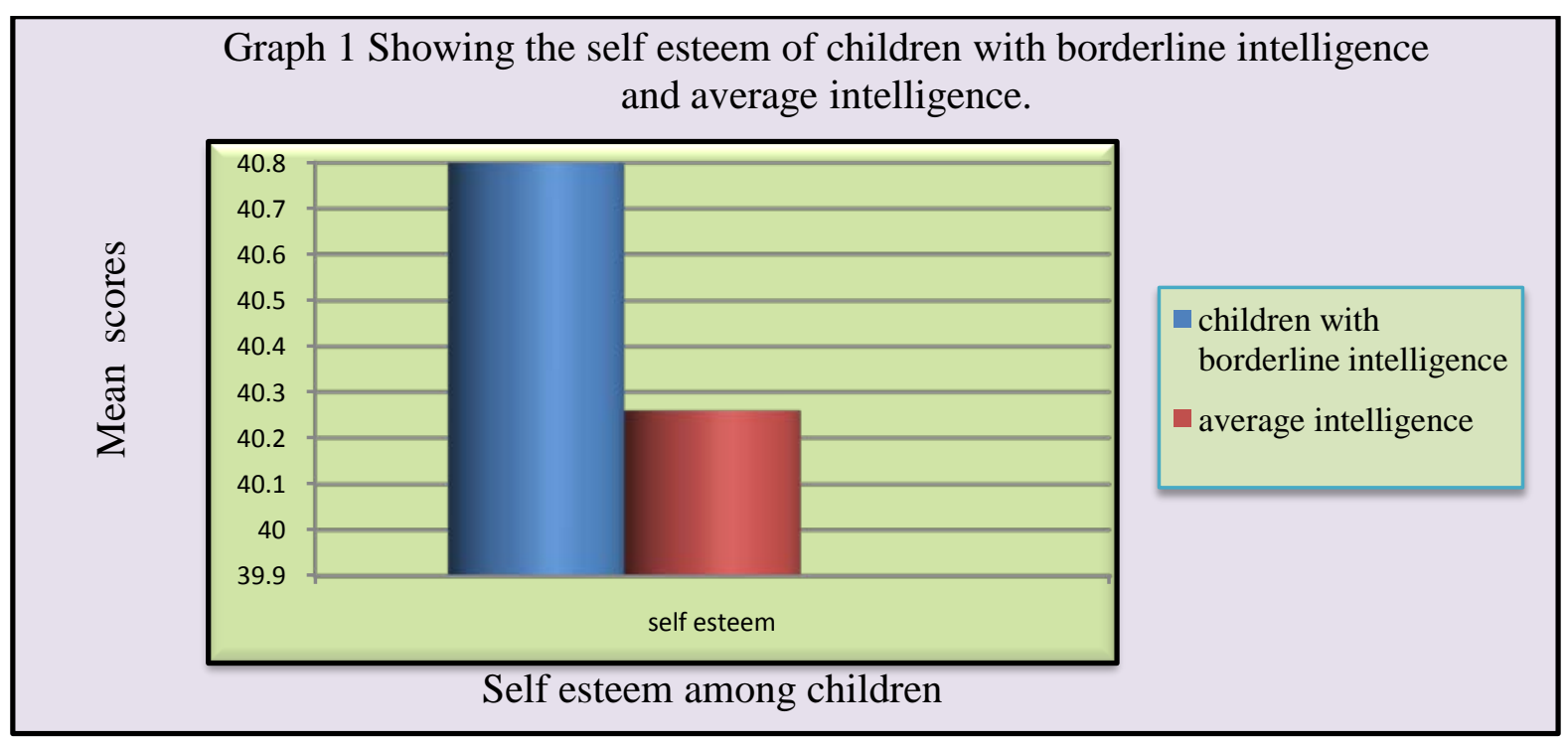


Graph 2 Showing the coping among children with borderline intelligence and average intelligence.

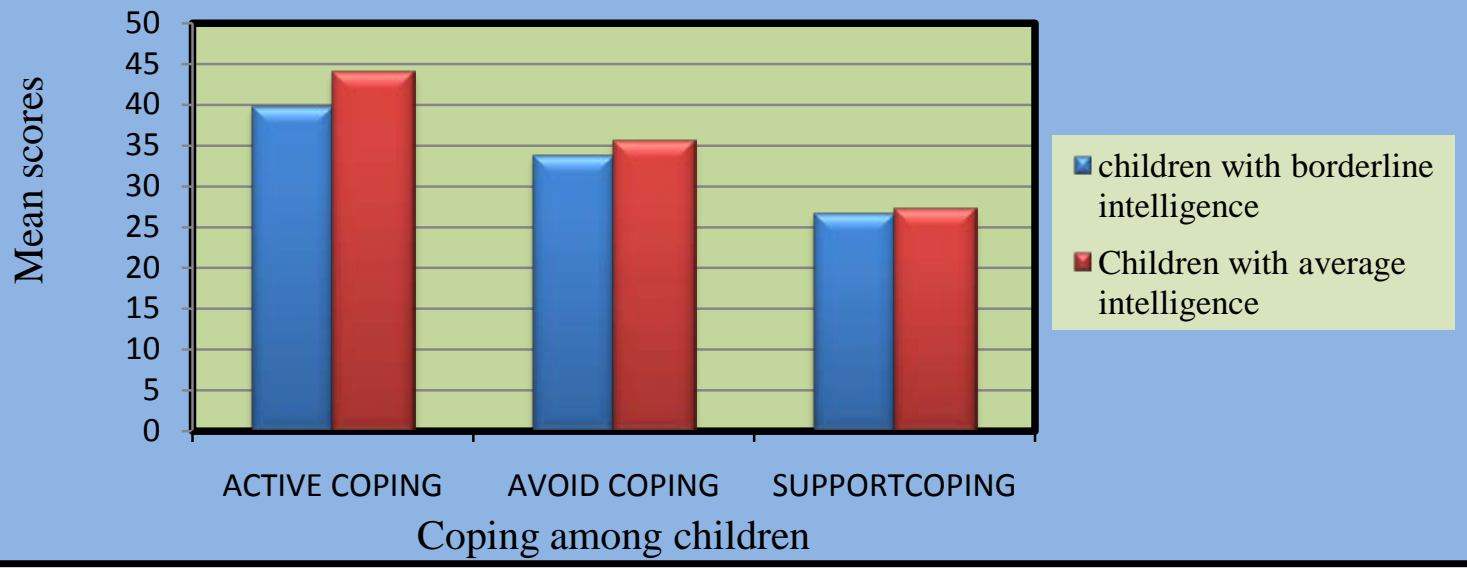

Table 1 shows the demographic details of 60 individuals who were the sample for the study. Of the 60 individuals, 30 were borderline intelligence and 30 were average intelligent studying in government and private school. The age of these individuals ranged between 8-12 years, of which 15 girls and 15 boys were borderline intelligence and 15 boys and 15 girls were average intelligence respectively. Of which 4 borderline intelligence boys belonged to 8-9 years category, 4 borderline intelligence boys belonged to 9-10 years category, 4 borderline intelligence boys belonged to 10-11 years category and 5 borderline intelligence boys belonged to 11-12 years category. 3 borderline intelligent girls belonged to 8-9 years category, 3 borderline intelligence girls belonged to 9-10 years category, 3 borderline intelligence girls belonged to 10-11 years category and 4 borderline intelligence girls belonged to 11-12 years category. 2 average intelligent boys belonged to 8-9 years category, 4 average intelligent boys belonged to 9-10 years category, 2 average intelligent boys belonged to 10-11 years category and 3 average intelligent boys belonged to 11-12 years category. 4 average intelligent girls belonged to 8- 9 years category, 5 average intelligent girls belonged to 9-10 years category, average intelligent girls belonged to 10-11 years category and 5 average intelligent girls belonged to 11-12 years category.

Table 2 shows the Mean, SD and ' $t$ ' value obtained for esteem and coping among children with borderline intelligence and average intelligence. For self esteem the mean secured by children with borderline intelligence and average intelligence were 40.80 and 40.26 respectively, with ' $t$ ' value being 0.16 which was significant at 0.05 level, indicating that there was significant difference in self esteem between children with borderline intelligence and average intelligence. The children with average intelligence show significantly less self esteem than children with borderline intelligence. The results are not according to the hypothesis stated that there will be no significant difference in self-esteem between borderline intelligence and average intelligence children. 


\section{Self-Esteem and Coping among Children with Borderline Intelligence and Average Intelligence}

For active coping the mean secured by children with borderline intelligence and average were 39.76 and 44.00 respectively, with ' $t$ ' value being 1.34 which was significant at 0.05 level, indicating that there was significant difference in active coping between children with borderline intelligence and average intelligence. The children with borderline intelligence show significantly less active coping than children with average intelligence. The results are not according to the hypothesis stated that there will be no significant difference in active coping between borderline intelligence and average intelligence children.

For avoid coping mean secured by children with borderline intelligence and average were 33.83 and 35.60 respectively, with ' $t$ ' value being .87 which was significant at 0.05 level, indicating that there was significant difference in avoid coping between children with borderline intelligence and average intelligence. The children with borderline intelligence show significantly less avoid coping than children with average intelligence. The results are not according to the hypothesis stated that there will be no significant difference in avoid coping between borderline intelligence and average intelligence children.

For support coping mean secured by children with borderline intelligence and average were 26.66 and 27.23 respectively, with ' $t$ ' value being 0.36 which was not significant at 0.05 level, indicated that there was no significant difference in support coping between children with borderline intelligence and average intelligence. Though there was no significant difference in coping children with borderline intelligence showed less support coping than children with average intelligence. The results are not according to the hypothesis stated that there will be no significant difference in support coping between borderline intelligence and average intelligence children.

The graph 1 shows the self esteem among children with borderline intelligence and average intelligence. The bar graph indicates an inclination in the self esteem for children with average intelligence than the children with borderline intelligence.

The graph 2 also shows the active coping, avoid coping, and support coping among children with borderline intelligence and average intelligence. The bar graph shows an inclination in bar for all coping methods for borderline intelligence than for average intelligence.

\section{CONCLUSION}

The children with average intelligence showed significantly less self esteem than children with borderline intelligence.

As there was significant difference in self esteem between children with borderline intelligence and average intelligence, the results are not according to the hypothesis stated that there will be no significant difference in self-esteem between borderline intelligence and average intelligence children. 
The children with borderline intelligence show significantly less active coping than children with average intelligence.

As there was significant difference in active coping between children with borderline intelligence average intelligence, the results are not according to the hypothesis stated that there will be no significant difference in active coping between borderline intelligence and average intelligence children.

The children with borderline intelligence show significantly less avoid coping than children with average intelligence.

As there was significant difference in avoid coping between children with borderline intelligence average intelligence, the results are not according to the hypothesis stated that there will be no significant difference in avoid coping between borderline intelligence and average intelligence children.

The children with borderline intelligence show less support coping than children with average intelligence.

As there was no significant difference in support coping between children with borderline intelligence average intelligence, the results are according to the hypothesis stated that there will be no significant difference in support coping between borderline intelligence and average intelligence children.

\section{REFERENCES}

Aine, D, \& Lester, D. (1995). Exercise, depression, and self-esteem. "Perceptual and Motor Skills", 81, 890.

Alfermann, D, \& Stoll, O. (2000). Effects of physical exercise on self-concept and wellbeing. "International Journal of Sport Psychology", 30, 47-65.

Anthony, D. B, Holmes, J. G, \& Wood, J. V. (2007). Social acceptance and self-esteem: Tuning the sociometer to interpersonal value. "Journal of Personality and Social Psychology", 92, 1024-1039.

Ayers, T.S, Sandler, I.N, Bernzweig, J.A, Harrison, R.J, Wampler, T.W, \& Lusting, J.L. (1989). "Handbook for the content analyses of children's coping responses". Tempe: Program for Prevention Research Arizona State University.

Ayers, T.S, Sandler, I.N, West, S.G, \& Roosa, M.W.(1996). A dispositional and situational assessment of children's coping: Testing alternative models of coping "Journal of personality", 64,923-958.

Ayers, T.S, Sandler, I.N, West, S.G., \& Roosa, M.W. (1990, August). “Assessment of children's coping behaviors: testing alternative models of children's coping”. Paper presented at the American Psychological Association, Boston, MA. 
Ayers,T.S. (1991). “A dispositional and situational assessment of children's coping: Testing alternative theoretical models”. Unpublished Dissertation, Arizona state University, Tempe.

Battle, J. (1981). Culture free Self Esteem Inventory: "Self Esteem Inventories for Children and Adults Seattle". Special child Publications.

Battle, J. (1981). "Culture-free SEI self-esteem inventories for children and adults". Washington: J. B. Preston.

Battle, J. (1991). "Self-esteem research: A summary of relevant findings". Edmonton, Alberta: James Battle and Associates.

Battle, J. 1981. "Culture-free SEI: Self esteem inventories for children and adults”. Washington: Special Child Publications.

Baumeister, R. (Ed.). (1993). Self-esteem: "The puzzle of low self-regard”. New York: Plenum Press.

Baumeister, R. F. (1982). Self-esteem, self presentation, and future interaction: A dilemma of reputation. “Journal of Personality”, 50, 29-45.

Blascovich, J, \& Tomaka, J. (1991). Measures of self-esteem. In J. P. Robinson, P. R. Shaver, \& L. S. Wrightsman (Eds.), "Measures of personality and social psychological attitudes. Volume 1 of Measures of social psychological attitudes" (pp. 115-160). San Diego, CA: Academic Press.

Bynner, J. M., P. M. O'Malley, and J. G. Bachman. 1981. Self-Esteem and Delinquency Revisited." Journal of Youth and Adolescence "10(6): 407-444.

Campbell, J. D. (1990). Self-esteem and clarity of the self-concept. "Journal of Personality and Social Psychology", 59, 538-549.

Cohen, A. R. 1959. Some Implications of Self-Esteem for Social Influence. In "Personality and Persuasibility”, by I. L. Janis et al., 102-120. New Haven, Conn.: Yale University Press.

Crandall, R. 1973. The Measurement of Self-Esteem and Related Constructs. In "Measures of Social Psychological Attitudes”, edited by J. P. Robinson and P. R. Shaver, 45-168. Ann Arbor, Mich.: Institute for Social Research.

Delaney, W, \& Lee, C. (1995). Self-esteem and sex roles among male and female high school students: Their relationship to physical activity. “Australian Psychologist”, 30, 84-87.

Denissen, J. J. A, Penke, L, Schmitt, D. P, \& van Aken, M. A. G. (2008). Self-esteem reactions to social interactions: Evidence for sociometer mechanisms across days, people, and nations. "Journal of Personality and Social Psychology", 95(1), 181-196.

Finkenberg, M. E. (1990). Effect of participation in taekwondo on college women's selfconcept. "Perceptual and Motor Skills", 71, 891-894.

Ford, H. T. Jr, Puckett, J. R., Reeve, T. G, \& Lafavi, R. G. (1991). Effects of selected physical activities on global self-concept and body-cathexis scores. "Psychological Reports", 68, 1339-1443.

Furnham, A, Badmin, N, \& Sneade, I. (2002). Body image dissatisfaction: Gender differences in eating attitudes, self-esteem, and reasons for exercise. "The Journal of Psychology", 136, 581-596. 


\section{Self-Esteem and Coping among Children with Borderline Intelligence and Average Intelligence}

Harter, S. (1993). Causes and consequences of low self-esteem in children and adolescents. In R. F. Baumeister (Ed.), "Self-esteem: The puzzle of low self-regard”. New York: Plenum.

Jump up "Diagnostic and statistical manual of mental disorders": DSM-IV. Washington, DC: American psychiatric Association. (2000).

Jump up to: a b c "The Best Test Preparation for the Advanced Placement Examination in psychology”, Research \& Education Association. (2003), p.99

Jump up TP Alloway (May 2010). "Working memory and executive function profiles of individuals with borderline intellectual functioning” 54(5). Pp. 448-56.

Kernis, M. H, Cornell, D. P, Sun, C, Berry, A, \& Halow, T. (1993). There's more to selfesteem than whether it is high or low: The importance of stability of self-esteem. "Journal of Personality and Social Psychology”, 65, 1190 - 1204.

Leary, M. R, \& Baumeister, R. F. (2000). The nature and function of self-esteem: sociometer theory. In M.P. Zanna (Ed.), “Advances in experimental social psychology”: Vol. 32 (pp. 1- 62). San Diego: Academic Press.

Leary, M. R, Gallagher, B, Fors, E, Buttermore, N, Baldwin, E, Kennedy, K, \& Mills, A. (2003). The invalidity of disclaimers about the effects of social feedback on self-esteem. “Personality and Social Psychology Bulletin”, 29, 623-636.

Leary, M. R, Schreindorfer, L. S, \& Haupt, A. L. (1995). The role of self-esteem in emotional and behavioral problems: Why is low self-esteem dysfunctional? "Journal of Social and Clinical Psychology”, 14, 297-314.

McAuley, E, Blissmer, B, Katula,, J, Duncan, T. E, \& Mihalko, S. L. (2000). Physical activity, self esteem, and self-efficacy relationships in older adults: "A randomized controlled trial. Annals of Behavioral Medicine”, 22, 131-139.

Pitts, S.C, Tein, J.Y, \& Sandler, I.N. (1995, March). “Applying jackknife techniques to a three factor model of coping”. Paper presented at the Seventy-fifth Western Psychology Association Annual Conference, Los Angeles. CA.

Pullmann, H. \& Allik, J. (2000). The Rosenberg self-esteem scale: Its dimensionality, stability and personality correlates in Estonia. "Personality and Individual Differences 28”, 701715.

Ramsdern, S, Richardson, F. M, Josse, G, Thomas, M. S. C, Ellis, C, Shakeshaft, C, Seghier, M. L., \& Price, C. J. (2011). "Verbal and non - verbal intelligence changes in the teenage brain” NATURE, 479.

Roosa. M.W, Sandler, I.N, Gehring, M, Beals, J, \& et al. (1998). The Children of alcoholics lifeevents schedule: A stress scale for children of alcohol-abusing parents. "Journal of studies on Alcohol”, 49(5), 422-429.

Rosenbaum, M. E, and R. de Charms. 1962. Self-Esteem and Overt Expressions of Aggression. “In Decisions, Values, and Groups”, vol. 2, edited by N. F. Washburne, 291-303. New York: Pergamon.

Sandler, I.N, Ayers, T.S, Bernzweig, J.A, Wampler, T.P, Harrison, R.H, \& Lustig, J.L, (1990 August). "Children coping with divorce-related stressful events". Paper presented at the American Psychological Association, Boston, MA. 
Stotl and, E, and J. Martinez. 1976. Self-Esteem and Mass Violence at Kent State. “International Journal of Group Tensions” 6: 4-54.

Stotl and, E. 1976. Self-Esteem and Violence by Guards and Troopers at Atrica. "Criminal Justice and Behavior" 3: 85-96.

Tafordi, R. W, \& Milne, A. B. (2002). Decomposing global self-esteem. “Journal of Personality”, 70, 443-483.

Tiggemann, M. (2001). The impact of adolescent girls' life concerns and leisure activities on body dissatisfaction disordered eating, and self-esteem. "The Journal of Genetic Psychology", 162,133-142.

Tiggemann, M., \& Williamson, S. (2000). "The effect of exercise on body satisfaction and selfesteem as a function of gender and age". Sex Roles, 43, 119-127.

Vohs, K. D, \& Heatherton, T. F. (2003). The effects of self-esteem and ego threat on interpersonal appraisals of men and women: A naturalistic study. "Personality and Social Psychology Bulletin”, 29, 1407-1420.

Wilson, J. (2014, Feb.19). What your IQ score doesn't tell you CNN Health. Retrieved from htt:/www.cnn./2014/02/19/health/iq-score-meaning/. 